\section{No diga fake news, di desinformación: una revisión sobre el fenómeno de las noticias falsas y sus implicaciones}

\section{Do not say fake news; say disinformation: a review article about the fake news phenomenon and its implications}

DOI: http://dx.doi.org/10.18566/comunica.n40.a05

Recibido: 31/01/2019 - Aceptado: 29/05/2019

\section{Resumen}

Las fake news se han convertido en un fenómeno mundial en el consumo de información online. Este artículo pretende analizar los conceptos desinformación y fake news, sus implicaciones y consecuencias, así como suscitar una reflexión sobre el fenómeno y su apropiación discursiva. Además, se propone sustituir el concepto fake news por el de desinformación por cuatro razones: fake news no abarca todas las dimensiones de la desinformación que abundan en internet (medios de comunicación fallidos, bulos, información tendenciosa o engañosa, información manipulada o propaganda), el oxímoron propio del término, la absorción del término por el discurso político para desacreditar la labor del periodista y la motivación económica e ideológica que subyace a la generación de fake news. La desinformación hace referencia a la distorsión de la información difundiendo noticias falseadas que engañan al receptor final. Como respuesta a la corriente de desinformación el periodismo de verificación de hechos parece posicionarse como el único cortafuego real con el propósito de mejorar la calidad del debate público.

\section{Abstract}

Fake news has become a worldwide phenomenon in relation to the consumption of online information. This article aims to analyze the disinformation and fake news concept, its implications and consequences
Comunicación

número 40

Enero-junio

2019 | pp. 65-74

\section{Carlos \\ Rodríguez Pérez}

Profesor de Comunicación

Social y Periodismo de la

Universidad de Ibagué.

Doctorando en Ciencias

de la Información en la

Universidad Complutense

de Madrid. Magíster en

Comunicación Política

e Institucional en el

Instituto Universitario de

Investigación Ortega y

Gasset de Madrid y Magíster en Márketing, Consultoría y

Comunicación Política en la

Universidad de Santiago de

Compostela. Graduado en

Periodismo y Graduado en

Comunicación Audiovisual

en la Universidad Carlos

III de Madrid. Correo

electrónico: carlos.

rodriguez@unibague.edu.co | carloscompol@gmail.com https://orcid.org/0000-

0002-4830-5554

Palabras clave

Fake news, desinformación, fact checking, periodismo, redes sociales.

Keywords

Fake news, disinformation, fact-checking, journalism, social networks. 
as well as to provoke a reflection on the phenomenon and its discursive appropriation. Moreover, this article proposes replacing the concept of fake news with disinformation for four reasons: fake news does not cover all the dimensions of disinformation that abound on the Internet (failed media, hoaxes, biased or misleading content, manipulated information, or propaganda); the term is an oxymoron; it has been taken over by political discourse to discredit the work of journalists; and there is an underlying economic and ideological motivation in generating fake news. In contrast, disinformation refers to the distortion of information by spreading false news that deceives the final recipient. In response to the trend of disinformation, fact-checking journalism is apparently the only real firewall with the goal of improving the quality of public debate.

\section{Introducción}

Internet y el ciberespacio ponen al servicio de los ciudadanos un cátering de fuentes de información. Una época de abundancia en la que las redes sociales son también un canal más al que recurren los ciudadanos para informarse, especialmente los jóvenes (European Commission, 2016; Pew Research Center, 2018).

El consumo de información online vive actualmente una etapa convulsa producto de la desinformación que abunda en la red. El camuflaje de muchos contenidos disfrazados como noticias está minando internet de fake news (bulos o paparruchas), propaganda, contenidos engañosos, mentiras e información manipulada. Las consecuencias se palpan en discursos polarizados y en la radicalización de las opiniones, la desinformación de la población e indirectamente en la menor confianza hacia la actividad periodística y los medios de comunicación producida por una doble dinámica: los ataques a los medios de comunicación y periodistas por parte de líderes políticos y la espiral de escepticismo que genera tanta desinformación hacia el crédito de la profesión periodística. El informe que publica anualmente el Instituto Reuters (2018) identificó las fake news como una de las variables que se vinculan directamente con la confianza en los medios. En este escenario de tribulación en el que no para de crecer el consumo de información a través de plataformas sociales como WhatsApp, Facebook o Twitter y buscadores como Google, las generaciones más jóvenes emergen como sus principales consumidores y los usuarios mayores de 65 años como sus principales víctimas: en la campaña presidencial de los Estados Unidos del 2016, este grupo compartió siete veces más fake news que las cohortes más jóvenes (Guess et al., 2019). Sin ir más lejos, 50 de las historias fake más virales en Facebook durante el año 2018 obtuvieron más de 22 millones de reacciones (Silverman \& Pham, 2018). 
El fenómeno de la desinformación y de las fake news ha despertado el interés de la academia para diagnosticar y analizar las causas, consecuencias y posibles soluciones (Valero y Oliveira, 2018). No obstante, dicha investigación apunta a que solo el 32\% de los textos seleccionados propone soluciones al problema de la desinformación, entre las que figuran la alfabetización, el periodismo de verificación, la inteligencia artificial mediante la aplicación de algoritmos y el abordaje de la neutralidad de la red mediante el bloqueo de sitios webs.

En este artículo pretendemos analizar el concepto fake news, sus implicaciones y consecuencias. Así mismo, nos centramos en el periodismo de verificación como respuesta periodística para atajar el problema de la desinformación. El objetivo es suscitar una reflexión sobre el fenómeno, sus diferentes implicaciones y su apropiación discursiva. Además, este artículo pretende exponer la importancia que tiene para la industria periodística renovar sus procesos profesionales para salvaguardar la veracidad y calidad de la información propia, desmentir las fake news que circulan principalmente en entornos digitales y controlar los flujos de desinformación.

\section{Cuatro razones para hablar de desinformación}

En primer lugar, el fenómeno de la desinformación - information disorder (Wardle \& Derakhshan, 2017) es más amplio que lo evocado por el popular y transgresor concepto de fake news. Popular por el alcance y propagación para designar los contenidos informativos fraudulentos (Corner, 2017) difundidos a lo largo y ancho del globo terráqueo. Esta popularidad es la principal fortaleza de un término que permite recoger en su significado un imaginario común para referirnos a la desinformación. Sin embargo, la reducción y simplificación del fenómeno al concepto fake news es tanto un hándicap como un elemento transgresor por la antítesis suigéneris del concepto que explicamos en el segundo razonamiento. La desinformación, como fenómeno, hace referencia tanto al contenido informativo fraudulento (fake news) como al engañoso (misleading content), los discursos de odio (malinformation), los discursos falsos deliberados (false speech) o los errores informativos no deliberados de medios o periodistas (missinformation). Desinformación, por tanto, es la distorsión de la información difundiendo noticias falseadas que engañan al receptor final.

En segundo lugar, fake news es un oximoron por la sencilla razón de que lo falso y lo espurio no es noticia sino una narrativa de ficción. La noticia, como narración de lo real, relata hechos poniendo el conocimiento de la vida diaria a disposición del público. La noticia es, ante todo, "un hecho verdadero, inédito o actual de interés general" (Martínez Albertos, 1974). El quehacer periodístico fluye desde la responsabilidad social inherente a la 
profesión y que consiste en informar para que el conocimiento haga carne en la sociedad: el periodismo es el oficio de contar lo que pasa (Gabilondo, 2011) para hacer comprensible el mundo en el que vivimos (Diezhandino, 1994). El compromiso del periodista es convertir la información en conocimiento.

Lo fake es lo que se encuentra en las antípodas de la información periodística por ser un contenido informativo fraudulento. La difusión de chismes, mentiras e información falsa es inherente al ser humano; lo que ha cambiado en los últimos años es la velocidad de transmisión y la facilidad de generarlas y propagarlas dadas las características propias de internet (instantaneidad, interactividad, viralización y globalización de la información) que multiplican las posibilidades de quedar atrapado en la red de la desinformación. Dicho peligro en asociación con las carencias técnicas y formativas de la población y las dificultades de los profesionales de la información y la comunicación para detectar, combatir y contener dicho fraude elevan la gravedad del asunto, ante el cual buscadores y plataformas sociales aún no han desarrollado mecanismos efectivos para evitar su propagación.

La desinformación pone en jaque una de las variables imprescindibles de las democracias: el derecho a recibir una información veraz. Las democracias como sistemas deliberativos y abiertos se enfrentan a este problema sin saber muy bien cómo detenerlo todavía y confiando en la resiliencia ciudadana. De hecho, en 2018 un 73\% de los europeos mostró su preocupación por la desinformación en los periodos que antecedían las elecciones (European Commission, 2018). La incidencia en procesos políticos básicos como las campañas electorales (por ejemplo, en la campaña electoral de los Estados Unidos del 2016 ganada por Donald Trump o la campaña electoral brasileña del 2018 con victoria de Jair Bolsonaro) y los referéndums (como el del Brexit en Reino Unido) otorgan los primeros envites a la desinformación. En Colombia, el fenómeno de la desinformación y las fake news se cruzó con el referéndum del 2016 sobre los acuerdos de paz. Más recientemente, a comienzos del 2019, se viralizaron imágenes de soldados estadounidenses en territorio colombiano rumbo a Venezuela. Estos son solo algunos ejemplos de la incidencia de la propagación de las fake news que rápidamente infectan la conversación digital en las redes sociales.

Varios estudios recientes han establecido dos importantes hallazgos sobre la difusión de las fake news en la red social Twitter y su relación con perfiles de usuarios. En primer lugar, Vosoughi et al. (2018) realizaron un estudio sobre la difusión de contenidos verdaderos y falsos en Twitter (2006-2017) y su conclusión principal señala que las noticias falsas se propagan a mayor velocidad y tienen más alcance que las noticias verdaderas y sus efectos son más pronunciados si versan sobre política. En segundo lugar, Grinberg et al., (2019) exploraron el perfil de votantes y usuarios de Twitter que estuvieron 
expuestos y compartieron noticias falsas durante la campaña presidencial norteamericana del 2016. Su conclusión revela que, pese al problema general que desencadena la desinformación, solo el 1\% de la muestra consumió el $80 \%$ de las fake news y solo el $6 \%$ las compartió, siendo el 0,1\% responsable del 80\%. Es decir, únicamente una fracción exigua de ideología conservadora y de edad avanzada compartió fake news.

No obstante, varios autores apuntan tanto hacia la amenaza que supone la desinformación para los sistemas democráticos (Crilley \& Gillespie, 2018; Steensen, 2018), como alertan del posicionamiento oligopólico de las plataformas sociales y buscadores (Facebook o Google) como surtidores de información (Mosco, 2018).

En tercer lugar, el concepto fake news ha sido absorbido por el lenguaje político para atacar a periodistas y medios de comunicación por publicar noticias contrarias a los intereses políticos, ideológicos o personales del líder político (Boyd-Barrett, 2018). El caso más sonado es el de Donald Trump quien no duda en desacreditar el quehacer periodístico con el calificativo de fake news.

En cuarto lugar, radican las motivaciones inherentes a la producción de fake news. Las fake news forman parte del ecosistema económico de la desinformación (Corner, 2017) auspiciadas por los ingresos por publicidad obtenidos a través del clickbait y la viralización del contenido. Desde un punto de vista ideológico, las fake news tienen el propósito de favorecer determinadas posturas ideológicas y candidatos políticos (Allcott \& Gentzkow, 2017).

Con la erosión de la confianza ciudadana hacia los medios de comunicación producto de las corrientes de desinformación online (Steensen, 2018), han surgido en los últimos años medios de comunicación dedicados exclusivamente a la verificación de hechos, datos y discursos. El fact checking journalism (o periodismo de verificación de hechos factuales) surge ante la imperiosa necesidad de discernir entre los verdadero y lo falso, entre lo que es verdad y mentira ante el abundante caudal de información que circula en internet. Para ello, contrastan las declaraciones con los hechos y con los mejores datos disponibles (Zommer, 2015). Su expansión surge por una triple necesidad: verificar los discursos, evidenciar el engaño y la mentira y mejorar la calidad del debate público.

En febrero de 2019, la red International Fact Checking Network contaba con 68 medios de comunicación adheridos que habían ratificado un Código de Principios que vela por la publicación de informes apartidistas sobre las declaraciones políticas, institucionales o de otros actores sociales; y por 
la transparencia en las fuentes informativas usadas, en la metodología realizada, en la financiación de la organización y en la subsanación de los errores que se puedan producir. En la ilustración 1 se observa la ubicación geográfica de dichos medios. Los medios han proliferado en Estados Unidos, Europa, Sudamérica, sudeste asiático y Australia. A su vez se observa el vacío en África, Centroamérica y el continente asiático.

\section{Ilustración 1. Mapa con la ubicación de las organizaciones adheridas la red International Fact Checking Network que cumplen el Código de Principios.}
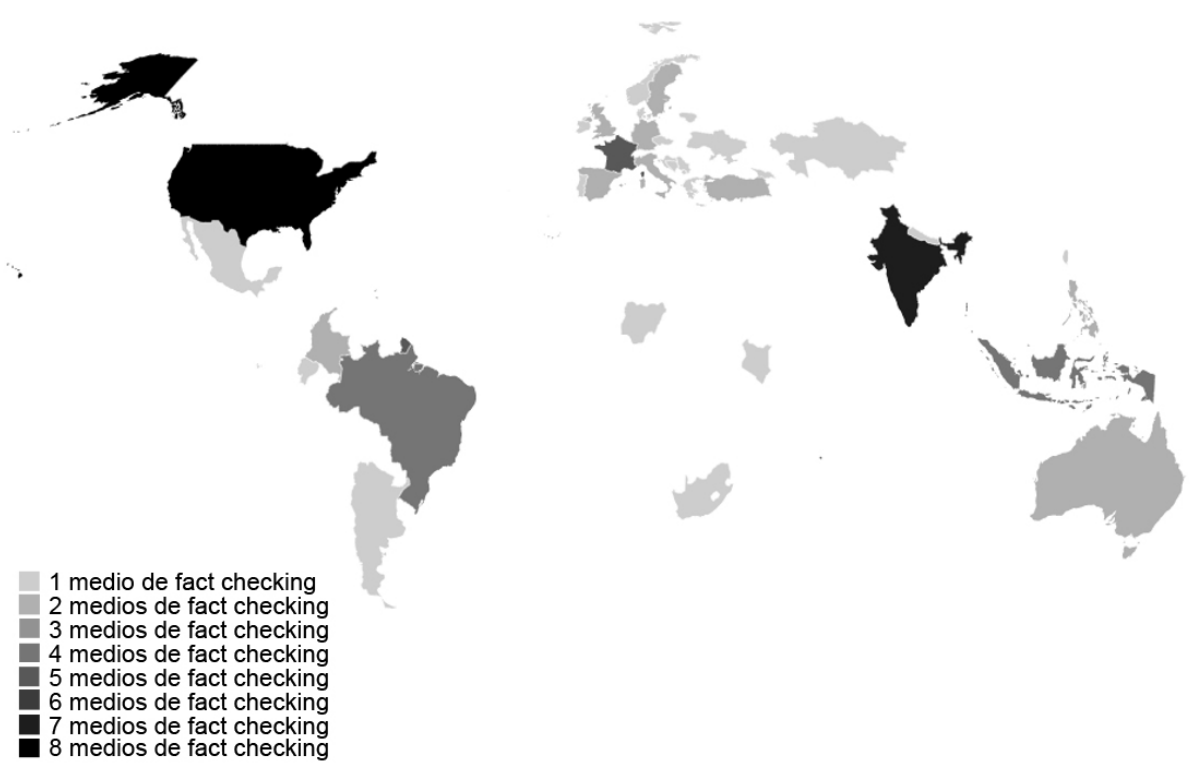

Fuente: elaboración propia (febrero 2019) a partir de información publicada por la red International Fact Checking Network.

La metodología del proceso de verificación suele contar con media docena de procedimientos a través de los cuales calificar el hecho factual. El medio de fact checking colombiano www.colombiacheck.com tiene seis pasos: selección de la frase, consulta al autor de la declaración, cotejo de la información de la declaración con fuentes oficiales y confiables, comprobación con fuentes alternativas y/o expertas, contextualización y calificación final. Por su parte www.chequeado.com, medio argentino de fact checking, aplica dos procedimientos adicionales para realizar la comprobación: ponderar la relevancia e interés social del hecho a verificar; y la confirmación, relativización o desmentido de la afirmación como paso previo a la calificación. 
El fact checking se guía por cuatro criterios para asegurar la pertinencia de su trabajo: la selección del hecho asegurando que se trata de algo factual y no de una opinión, para lo que además se tienen en cuenta los criterios de noticiabilidad (autoría, temática e interés humano), así como su circulación o viralización; la selección de fuentes (oficiales, expertas y alternativas) para verificar la información; la contextualización del hecho sujeto a comprobación y la asignación de una calificación a partir de unas categorías ya preestablecidas.

En Estados Unidos el medio de fact checking www. politiFact.com comprobó la veracidad de las afirmaciones de los dos candidatos a la presidencia durante la campaña presidencial del 2016. Los resultados fueron que el 70\% de las afirmaciones chequeadas a Donald Trump, a la postre presidente, eran falsas o mayoritariamente falsas; mientras que el porcentaje de afirmaciones falsas o mayoritariamente falsas asignadas a Hillary Clinton fue del 26\% (Lewandowsky et al., 2017). De hecho, hay autores que sugieren que sin la viralización de las fake news Trump no habría alcanzado la presidencia (Allcott \& Gentzkow, 2017).

La relevancia del proceso de verificación como antivirus a la desinformación es vital. De hecho, la colaboración estrecha entre redes sociales y el periodismo de verificación es una solución proactiva para atajar los problemas asociados a la desinformación (Grinberg et al., 2019) y detener así su propagación en el entorno digital.

La falta de verificación, filtros y la ausencia de responsabilidad de dichas plataformas sobre el contenido que en ellas se difunde apunta hacia uno de los mayores retos para el periodismo y para la democracia (Crilley \& Gillespie, 2018). No obstante, como observa Steensen (2018) la formación de opiniones, percepciones, evaluaciones y juicios sobre los procesos sociales no encajan con hechos aislados que pueden ser calificados en categorías dicotómicas como verdadero o falso, correcto o incorrecto; sino que forman parte de procesos discursivos o relatos elaborados con base en procesos cognitivos asentados en marcos sociolingüísticos - teoría del framing - (Entman, 1993; Lakoff, 2007; Luntz, 2007) en un clima político cada vez más polarizado.

\section{Conclusión}

Internet propaga dos libertades: la libertad de expresión y la libertad de información. Actualmente ambas están siendo reos del libertinaje del ciberespacio: la primera, por la polarización que provoca la conversación social infectada, a menudo, de trolls y bots en una cartografía que rezuma crispación y cámaras de eco; la segunda, por el desbordamiento de las 
corrientes de desinformación. Parafraseando lo que suele decir el periodista español Iñaki Gabilondo, cuando sucede una inundación lo que más se echa en falta es el agua potable. Hacia esto apunta internet: la inundación de desinformación, noticias manipuladas y mentiras en el discurso público y deliberativo en una era disruptiva que exacerbaba la libertad y la democratización de la información.

Desde el enfoque más pesimista (Han, 2014) las posibilidades ilimitadas de libertad en internet convierten la comunicación digital en un panóptico de control y vigilancia que ejerce un dominio activo sobre las corrientes de opinión pública en las que los flujos de desinformación se instalan con frecuencia. La información, como positividad, circula bien sin contexto o bien sin que el usuario pueda entender su contexto. Este panóptico se erige en las plataformas sociales cuya atribución de responsabilidad como contenedores y propagadores de la desinformación es aún escasa.

En este artículo se aboga por el concepto de la desinformación en vez del de fake news para abarcar las múltiples facetas en las que se propagan los bulos, contenidos engañosos o malintencionados. En primer lugar, señalamos la simplificación del concepto frente a la complejidad del fenómeno de la desinformación; en segundo lugar, el oxímoron propio del concepto fake news; en tercer lugar, la apropiación discursiva del concepto por parte de líderes políticos para desacreditar a medios y periodistas; $y$, en cuarto lugar, las motivaciones intrínsecas de carácter económico o ideológico vinculadas a la generación de fake news.

El auge de las plataformas sociales y su impacto como fuentes de información no solo percute en los ingresos de lo que hasta hoy hemos conocido como medios de comunicación, sino además en el socavamiento de la calidad de la democracia deliberativa de tres maneras: el uso de las plataformas sociales como propaganda política y contenidos engañosos; la propagación de discursos de odio, polarizados y radicalizados; y en el descenso en la legitimidad y confianza ciudadana hacia el quehacer periodístico (Crilley \& Gillespie, 2018).

Ni el periodismo como profesión ni las plataformas sociales de difusión de dichos mensajes (Facebook, Twitter, WhatsApp,...) son aún capaces de controlar los flujos de desinformación que abundan en internet. Recientemente están incorporando nuevas medidas como limitar el reenvío de mensajes, o destacar el contenido generado por personas en detrimento de organizaciones con el fin de evitar la propagación de bulos o información engañosa. Por su parte, el fact checking es un recurso eficaz y eficiente como revulsivo; sin embargo, es reactivo, requiere tiempo y actúa una vez la información falsa ya se ha viralizado: en internet la propagación de bulos tiene una celeridad desmesurada (Vosoughi et.al., 2018). Además, tal y como mostró Thorson 
(2016), la desinformación genera efectos en las actitudes de los receptores incluso cuando ya ha sido desacreditada y son conscientes de ello.

En el mundo de la comunicación y el periodismo el ciclo de producción de noticias (newsmaking) ha cambiado radicalmente (López-Borrull et.al., 2018). Procesos como la verificación de fuentes y datos, la desintermediación de los medios tradicionales por las redes sociales y la celeridad actual forman el nuevo estado informativo de la última hora y la actualización constante. Actualmente, solo el fact checking parece emerger como cortafuegos (Lotero Echeverri, Romero Rodríguez, \& Pérez Rodríguez, 2018). No obstante, existen otros incipientes mecanismos -digital forensics, source critism - (Steensen, 2018) para auditar y verificar el contenido multimedia y las fuentes informativas. Además, sigue latente la vinculación de redes sociales con periodistas especializados en verificación con el objetivo de analizar mensajes y perfiles dedicados a la propagación de la desinformación en cada una de sus vertientes. El peligro de las fake news no reside tanto en el sitio natural donde se reproducen sino en cómo infectan la agenda mediática tradicional y entran de lleno en las corrientes de opinión pública y en el debate público, especialmente aquellas que inciden en los cleavages políticos y sociales (inmigración, sistema de partidos, estado social,...). El proceso de verificación para cortarle las alas a la desinformación dependerá en buena medida de cómo responda el periodismo y las alianzas que pueda encontrar para hacer frente a este desafío.

\section{Referencias}

Allcott, H., \& Gentzkow, M. (2017). Social media and fake news in the 2016 election. Journal of Economic Perspectives, 31(2), 211-236. doi:10.1257/jep.31.2.211

Boyd-Barrett, O. (2018). Fake news and 'RussiaGate' discourses: Propaganda in the posttruth era. Journalism, 20(1), 87-91. doi:// doi.org/10.1177/1464884918806735

Corner, J. (2017). Fake news, post-truth and media-political change. Media, Culture e Society, 39(7), 1100- 1107. doi:// doi.org/10.1177/0163443717726743

Crilley, R., \& Gillespie, M. (2018). What to do about social media? Politics, populism and journalism. Journalism, 20(1), 173-176. doi:10.1177/1464884918807344

Diezhandino, M. P. (1994). El quehacer informativo: El" arte de escribir" un texto periodístico. Bilbao: Servicio Editorial Universidad del País Vasco.

Entman, R. M. (1993). Framing: Toward clarification of a fractured paradigm. Journal of Communication, 43(4), 51-58. doi://doi.org/10.1111/j.1460-2466.1993.tb01304.x

European Commission. (2016). Special eurobarometer 452. media pluralism and democracy. Recuperado de https: / / bit.ly/2gkbn6H

European Commission. (2018). Special eurobarometer 477. democracy and elections. Recuperado de https: / / bit.ly/2UTplwn 
Gabilondo, I. (2011). El fin de una época: Sobre el oficio de contar las cosas. Barcelona: Barril Barral.

Grinberg, N., Joseph, K., Friedland, L., Swire-Thompson, B., \& Lazer, D. (2019). Fake news on twitter during the 2016 US presidential election. Science, 363 (6425), 374-378. doi:10.1126/ science.aau2706

Guess, A., Nagler, J., \& Tucker, J. (2019). Less than you think: Prevalence and predictors of fake news dissemination on facebook. Science Advances, 5(1), 1-9. doi:10.1126/sciadv.aau4586

Han, B. (2014). Psicopolítica: Neoliberalismo y nuevas técnicas de poder. Barcelona: Herder Editorial. Lakoff, G. (2007). No pienses en un elefante: Lenguaje y debate político. Madrid: Editorial complutense.

Lewandowsky, S., Ecker, U. K., \& Cook, J. (2017). Beyond misinformation: Understanding and coping with the "post-truth" era. Journal of Applied Research in Memory and Cognition, 6(4), 353-369. doi://doi.org/10.1016/j.jarmac.2017.07.008

López-Borrull, A., Vives-Gràcia, J., \& Badell, J. (2018). Fake news, ¿amenaza u oportunidad para los profesionales de la información y la documentación? El Profesional De La Información (EPI), 27(6), 1346-1356. doi:// doi.org/10.3145/epi.2018.nov.17

Lotero Echeverri, G., Romero Rodríguez, L. M., \& Pérez Rodríguez, M. A. (2018). Fact-checking vs. fake news: Periodismo de confirmación como componente de la competencia mediática contra la desinformación. Index.Comunicación, 8(2), 295-316.

Luntz, F. (2007). Words that work: It's not what you say, it's what people hear. Hachette UK.

Martínez Albertos, J. L. (1974). Redacción periodística: Los estilos y los géneros en la prensa escrita. Barcelona: A.T.E.

Mosco, V. (2018). Social media versus journalism and democracy. Journalism, 20(1),181-184. doi:// doi.org/10.1177/1464884918807611

Pew Research Center. (2018). Social media outpaces print newspapers in the U.S. as a news source. Recuperado de https://pewrsr.ch/2UvWPSe

Reuters Institute. (2018). Digital news report 2018. Recuperado de https: / / bit.ly/2NCgL2g

Silverman, C., \& Pham, S. (2018). These are 50 of the biggest fake news hits on facebook in 2018. Recuperado de https: / / bit.ly/2TPKAiM

Steensen, S. (2018). Journalism's epistemic crisis and its solution: Disinformation, datafication and source criticism. Journalism, 20(1), 185-189. doi:// doi. org/10.1177/1464884918809271

Thorson, E. (2016). Belief echoes: The persistent effects of corrected misinformation. Political Communication, 33(3), 460-480. doi:// doi.org/10.1080/10584609.2015.1102187

Valero, P. P., \& Oliveira, L. (2018). Fake news: Una revisión sistemática de la literatura. Observatorio (OBS*), 12(5). doi:10.15847/obsOBS12520181374

Vosoughi, S., Roy, D., \& Aral, S. (2018). The spread of true and false news online. Science, 359(6380), 1146-1151. doi:10.1126/science.aap9559

Wardle, C., \& Derakhshan, H. (2017). Information disorder: Toward an interdisciplinary framework for research and policymaking. Council of Europe Report, DGI (2017), 9

Zommer, L. (2015). El boom del fact checking y la vuelta a las fuentes. In G. Roitberg, \& F. Piccato (Eds.), Periodismo disruptivo (pp. 194). Buenos Aires: La Crujía. 